\title{
A Putative Adverse Outcome Pathway Network for Disrupted Female Pubertal Onset to Improve Testing and Regulation of Endocrine Disrupting Chemicals
}

\author{
Delphine Franssen ${ }^{\mathrm{a}}$ Terje Svingen ${ }^{\mathrm{b}}$ David Lopez Rodriguez ${ }^{\mathrm{a}}$ \\ Majorie Van Duursen ${ }^{c}$ Julie Boberg ${ }^{b}$ Anne-Simone Parent ${ }^{a, d}$

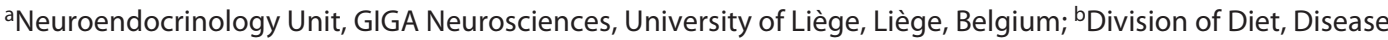 \\ Prevention and Toxicology, National Food Institute, Technical University of Denmark, Kongens Lyngby, Denmark; \\ ${ }^{c}$ Department of Environment and Health, Vrije Universiteit Amsterdam, Amsterdam, The Netherlands; ${ }^{\mathrm{d}}$ Department \\ of Pediatrics, CHU de Liège, Liège, Belgium
}

\section{Keywords}

Puberty - Hypothalamic-pituitary-gonadal axis .

Reproduction · Adverse outcome pathway · Endocrine disrupting chemicals

\begin{abstract}
The average age for pubertal onset in girls has declined over recent decades. Epidemiological studies in humans and experimental studies in animals suggest a causal role for endocrine disrupting chemicals (EDCs) that are present in our environment. Of concern, current testing and screening regimens are inadequate in identifying EDCs that may affect pubertal maturation, not least because they do not consider early-life exposure. Also, the causal relationship between EDC exposure and pubertal timing is still a matter of debate. To address this issue, we have used current knowledge to elaborate a network of putative adverse outcome pathways (pAOPs) to identify how chemicals can affect pubertal onset. By using the AOP framework, we highlight current gaps in mechanistic understanding that need to be addressed and simultaneously point towards events causative of pubertal disturbance that could be exploited for alternative test
\end{abstract}

methods. We propose 6 pAOPs that could explain the disruption of pubertal timing by interfering with the central hypothalamic trigger of puberty, GnRH neurons, and by so doing highlight specific modes of action that could be targeted for alternative test method development.

(c) 2021 S. Karger AG, Basel

\section{Introduction}

Puberty is a multifaceted process whereby a child develops into a reproductive mature individual. Central to this process is the reactivation and maturation of the hypothalamic-pituitary-gonadal (HPG) axis that leads to gonadarche. The average time of pubertal onset marked by breast development in girls is 10-11 years of age, whereas the average age of menarche is around 12-13 years. There has been a steady decline in age at pubertal onset and maturation over the last decades, attributed to both improved lifestyle $[1,2]$ and potential exposure to endocrine disrupting chemicals (EDCs) in the environment $[2,3]$. 
Late-onset puberty in girls appears to be associated with a slight decrease in bone density and increase in metabolic disorders [4], whereas early puberty is associated with increased risk of breast cancer [5], metabolic disorders such as insulin resistance and obesity [6], and depression and antisocial behavior [7] later in life. Prenatal and early postnatal disturbance of sexual development may also herald late-life fertility issues or reproductive disorders [8]. This association between EDC exposure, disturbed puberty, and a range of other reproductive disorders in women has prompted increased research focused on the issue, with emerging evidence for there being clear links between early-life exposure and late-life reproductive effects. However, our mechanistic knowledge about causal relationships between chemical exposure and disease outcomes remains inadequate with regard to devising robust chemical test strategies capable of detecting compounds that may be harmful to developing girls. To better address this shortcoming, we present a collection of putative adverse outcome pathways (pAOPs) that we believe will serve as signposts for future research and development on the area. We have chosen to focus the review on female puberty.

\section{HPG Axis Activation and Sexual Maturation}

Sexual maturation, or puberty, is initiated by a subset of hypothalamic neurons secreting gonadotropin-releasing hormone $(\mathrm{GnRH})$. These neurons release $\mathrm{GnRH}$ in a pulsatile manner into the hypophyseal portal blood system. In the anterior pituitary, GnRH binds to its receptor expressed by gonadotropic cells and induces the release of 2 gonadotropins, luteinizing hormone (LH) and follicle-stimulating hormone (FSH). In turn, LH and FSH stimulate gametogenesis and steroidogenesis. The release of sex steroids is therefore modulated by pituitary gonadotropic cells, which are themselves influenced by the frequency with which $\mathrm{GnRH}$ is released. Sex steroids modulate the activity of the HPG axis through positive and negative feedback loops (shown in Fig. 1) [9]. Estradiol and testosterone exert a negative feedback, which is active throughout development. Starting at puberty, estrogens also produce a positive feedback to induce ovulation in females [9].

Puberty results from an increase in $\mathrm{GnRH}$ pulsatile secretion. In female rats, hypothalamic GnRH content gradually increases during the first days of life. From day 12 , GnRH secretion becomes pulsatile and increases in frequency and amplitude until puberty [10-12]. This de- velopmental increase was reproduced ex vivo using incubation of hypothalamic explants [13]. As illustrated in Figure 2, a gradual increase in GnRH secretion frequency occurs in both sexes between postnatal days 5 and 25 [13]. This activation of pulsatile GnRH secretion causes an increase in LH and FSH secretion that will stimulate gonad maturation and thereby sex steroid production and release. Classically, the increase in GnRH secretion around puberty is considered to be under the control of a variety of hypothalamic genes organized in coordinated networks. The current hypothesis postulates that a loss of trans-synaptic inhibition, together with a rise in excitatory inputs, is responsible for the activation of GnRH release [14]. This rise in excitatory inputs is associated with the arrival of axonal projections from neurons in the arcuate nucleus (ARC), such as kisspeptin neurons, in the neighborhood of GnRH cell bodies in the preoptic area [15]. This results from a shift in expression of puberty activating and inhibiting genes during pubertal transition and a marked switch in the regulation of the GnRH promoter [16].

\section{Evidence for Industrial Chemicals Contributing to Disrupted Pubertal Onset}

Secular decrease in age at menarche took place between 1890 and 1960 and was probably caused by improvement in nutritional and socioeconomic status [1, 17]. While age at menarche appears to have stabilized, several American and European studies have indicated an advancement of breast development in girls over the last 30 years [18-20]. In addition, more recent data suggest that age distribution of pubertal signs is skewed towards earliness for initial pubertal stages and toward lateness for final pubertal stages $[3,21]$. Besides this worldwide secular trend, some specific populations appear to show a high prevalence of precocious puberty (breast development before the age of 8 in girls). In Belgium and other developed countries, migrating children have a markedly increased risk of sexual precocity [17]. Such rapid evolution of developmental landmarks led to the hypothesis that puberty timing could be affected by exposure to environmental factors.

Human populations are exposed to an increasing number of synthetic chemicals [22]. Among 85,000 chemicals in use, $\sim 1,000$ have been identified as having the ability to disrupt normal endocrine function [23]. These chemicals, often referred to as EDCs, are defined as any exogenous chemical, or mixture of chemicals, that 
Fig. 1. HPG axis. Secretion of GnRH governs the HPG axis by stimulating the release of LH/FSH, which in turn will induce the release of sex steroids by the gonads. Sex steroids exert negative feedback when their serum levels increase in order to stabilize their concentrations. At puberty, they can also exert positive feedback leading to the preovulatory $\mathrm{LH}$ surge in females. These feedbacks act through kisspeptin neurons. The release of $\mathrm{GnRH}$ is under the control of a complex network including neurotransmitters (GABA and Glu), neuropeptides (kisspeptin), glial factors and peripheral hormones (leptin). EDCs can disturb this regulating system at many levels. HPG, hypothalamic-pituitary-gonadal; GnRH, gonadotropin-releasing hormone; LH, luteinizing hormone; FSH, follicle-stimulating hormone; Glu, glutamate; EDCs, endocrine disrupting chemicals; RP3V, rostral periventricular area of the third ventricle; ARC, arcuate nucleus; E2, estradiol; Kiss, kisspeptin; Dyn, dynorphin; NKB, neurokinin B; KNDy: KNDy neurons

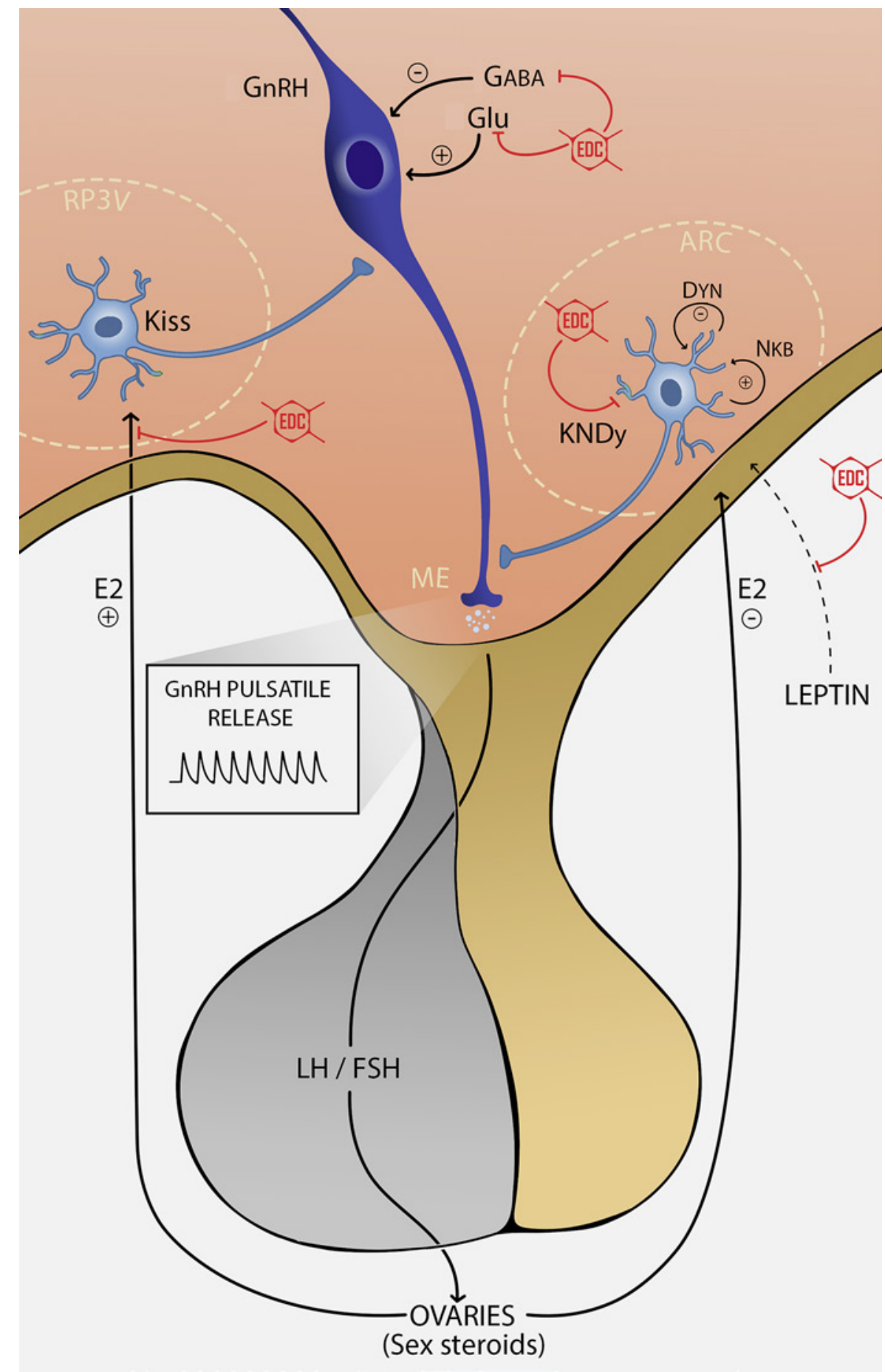

interferes with any aspect of hormone action and leads to adverse effects in an intact organism or its progeny [24]. EDCs are found in plastics (bisphenol A [BPA]) and plasticizers (phthalates), solvents and lubricants (polychlorinated biphenyls, polybrominated biphenyls, and dioxins), pesticides (methoxychlor, chlorpyrifos, and dichlo- rodiphenyltrichloroethane), and pharmaceutical agents (diethylstilbestrol [DES]). EDCs have a wide impact on populations given their ubiquitous presence in our environment. Reports about the advancing onset of puberty in several countries have led to the hypothesis that the increasing burden of EDCs could be a contributing factor. 
Fig. 2. Postnatal evolution of pulsatile $\mathrm{GnRH}$ secretion measured in vitro in the female rat. A gradual increase in GnRH secretion frequency occurs between postnatal days 5 and 25. Adapted from Bourguignon and Franchimont 1984 [12]. GnRH, gonadotropin-releasing hormone.

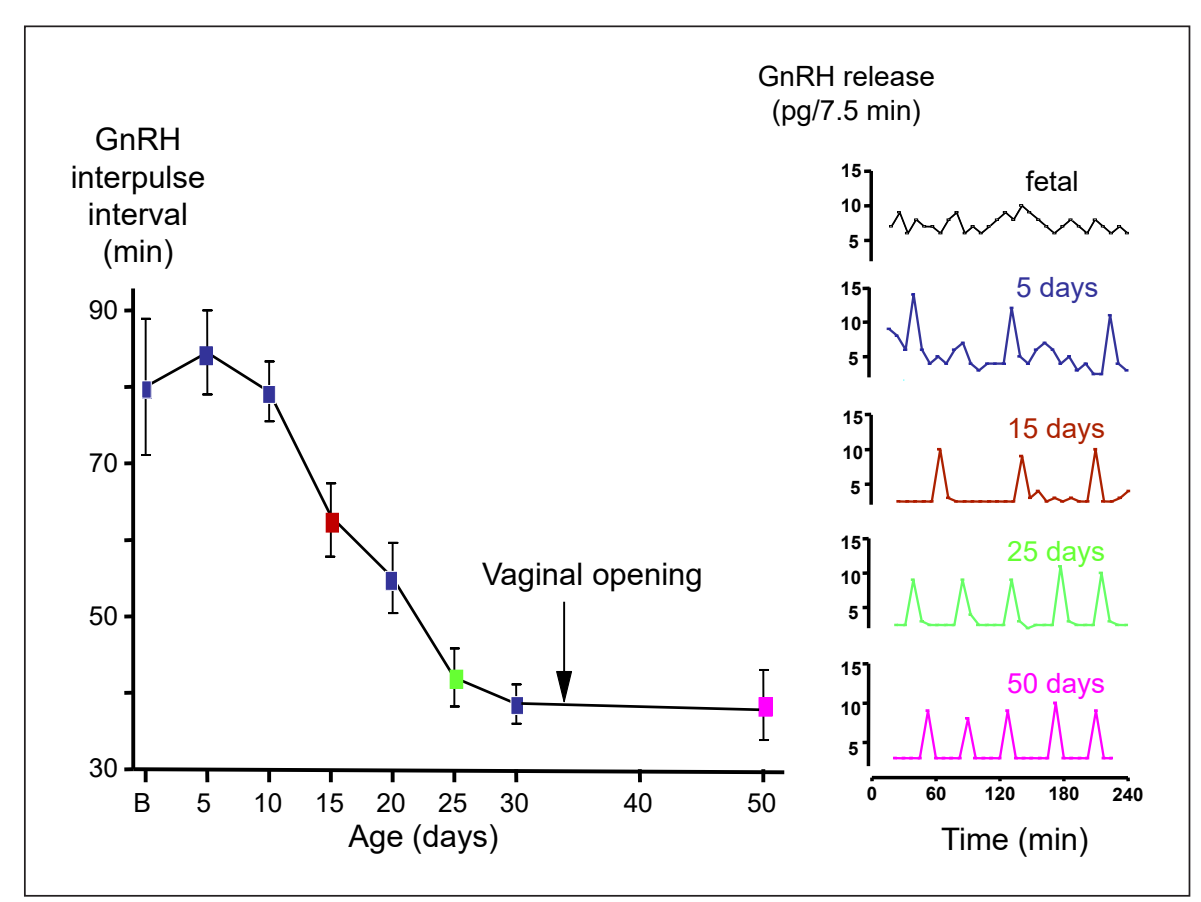

Demonstrating the effects of EDCs on human puberty is complex due to the concomitant exposure to a large number of EDCs, as well as the long and diverse period of exposure from conception onwards. However, some studies have identified that early-life exposure to EDCs could affect pubertal timing. Daughters of women working in greenhouses exposed to pesticides showed earlier breast development than daughters of unexposed women [25]. Recently, age at puberty was shown to be lowered by in utero exposure to phytoestrogens in a British cohort [26] while the consumption of soy products during infancy is linked to early menarche in girls in the same cohort [26] and to altered menstrual patterns in young adults in an American cohort $[27,28]$. Exposure to flame retardants such as PBDEs also appears to affect puberty timing in girls with effects depending on timing of exposure [29-31]. Finally, several animal models of EDC exposure have confirmed the impact of EDCs on pubertal timing, as reviewed by Parent et al. [3]. However, mechanisms of action remain incompletely understood. This hampers the development and use of test methods for chemical risk assessment, including nonanimal screening methods. Addressing this shortcoming is central to our current Horizon 2020 project FREIA, where we use the AOP framework specifically to guide future efforts by us and others to elaborate new and improved test strategies $[32,33]$. In the following, we propose to clarify additional mechanisms of interest using the AOP approach.

\section{The AOP Concept}

The AOP framework, or Knowledge Base (KB), is sponsored by the Organization for Economic Co-operation and Development (OECD) and serves as a central hub for AOP resources (https://aopkb.oecd.org/index. html). Within the AOP-KB, AOP Wiki (https://aopwiki. org/) serves as the primary repository for AOPs developed as part of the OECD AOP Development Effort by the Extended Advisory Group on Molecular Screening and Toxicogenomics. These online sites provide extensive resources for those wishing to learn more or themselves contributing towards advancing toxicological risk assessment and regulation efforts. Below, we will only describe the basic components of an AOP.

An AOP is a pragmatic description of the mechanistic principles underpinning cause-effect relationships leading up to an adverse effect in an intact organism. An AOP is assembled from a set of building blocks [34] starting with a molecular initiating event (MIE; a direct interaction between a chemical and a molecular target). This initial interaction triggers subsequent key events (KEs; a measurable change in biological or physiological state necessary to progress through the AOP), finally culminating in an adverse outcome (AO; an observable change in biological or physiological state of an intact organism typically of regulatory significance). Finally, the various KEs are linked by key event relation- 
ships (KERs), which are biologically plausible and scientifically based relationships describing causal and predictive connections between events. KERs are thus essential components of any encyclopedic AOP, as they allow us to predict that an $\mathrm{AO}$ is likely to manifest based only on data from upstream KEs or MIEs. This is the essential principle behind the AOP concept, to facilitate the use of nonanimal test methods to predict adversity in intact organisms based on mechanistic understanding of toxic responses.

Although AOPs are similar to classical molecular pathways describing normal development or disease etiologies [35], there are clear distinctions. Firstly, an AOP should be of relevance to chemical risk assessment or regulatory decision-making. The AO should thus be of regulatory significance and describe an observable pathological or clinical effect in an intact organism that is indicative of a disease state resulting from exposure to a toxicant [36]. Notably, however, AOPs are strictly biological descriptions not defined by any specific chemical [37]. Secondly, the various KEs should be limited only to those steps that are "both measurable and essential to the progression towards a specific AO" [38]. In other words, an AOP is not an exhaustive description of all the steps taking place between an MIE and an AO, but a short-hand version focusing on data that are usable for chemical risk assessment purposes. Thirdly, the KE string should be linked by biologically plausible and predictive relationships, or KERs, to facilitate the use of alternative test method data (e.g., in silico or in vitro) when determining potential chemical toxicity to intact organisms.

It is generally recognized that a single AOP is not necessarily robust enough to capture all toxic events that could result in a relevant toxic effect, or AO. But rather than constructing highly complex AOPs in an effort to address this shortcoming, the AOP thinking is to elaborate several related AOPs that can be linked through individual KEs to form the so-called AOP networks [39]. We recently proposed $10 \mathrm{pAOPs}$ for female reproductive disorders arising from early-life exposure to chemicals, where most were grouped in smaller networks, some of which themselves are connectable by additional shared KEs [33]. In this review, we expand on this AOP network by including $\mathrm{pAOPs}$ pertaining to disrupted pubertal timing in girls in response to EDC exposure.

\section{KE Relevant for Disrupted Onset Puberty in Girls}

In this review, we have developed pAOPs that could help explain the disruption of pubertal onset by EDC exposure and, by so doing, facilitate the development of additional test methods for chemical risk assessment purposes. All of these new pAOPs include a shared central element: modification of GnRH and LH/FSH release. As outlined in the Introduction section, pulsatile GnRH release increases to its maximum frequency at puberty when it induces a rise in $\mathrm{LH}$ and $\mathrm{FSH}$, ultimately leading to gonadal maturation. The pubertal increase in $\mathrm{GnRH}$ release results from a concurrent decrease in inhibitory inputs and increase in stimulatory signals on GnRH secretion. The exact nature of this upstream regulation is still incompletely understood. However, some major hypothalamic regulators such as GABA, glutamate, and kisspeptin neurons are known to act directly on GnRH neurons and to be controlled by transcriptional and peripheral factors.

\section{pAOPs Involving Kisspeptin Neurons}

pAOP-1: "Increased Activation of ER in RP3V Leads to Early Puberty"

This pAOP proposes to link an increase in estrogen receptor (ER) activation in the rostral periventricular area of the third ventricle (RP3V), leading to an early puberty via an elevated hypothalamic kisspeptin level (shown in Fig. 3).

\section{Supporting Evidence}

Kisspeptin is an essential activator of $\mathrm{GnRH}$ release during puberty, as evidenced by hypogonadotropic hypogonadic patients with mutations of the kisspeptin receptor [40,41]. There are 2 distinct hypothalamic populations of kisspeptin neurons in rodents, one in the $\mathrm{RP} 3 \mathrm{~V}$ which is sensitive to estrogens and mediates the estradiol positive feedback and one in the ARC, negatively regulated by estradiol [42]. The expression of Kiss1 mRNA, the number of kisspeptin neurons in RP3V, and their synaptic contacts with GnRH neurons increase just before the onset of puberty [43-45]. Studies in transgenic mice lacking ERa in kisspeptin neurons suggest that estrogens are necessary for increased expression of kisspeptin in RP3V during puberty $[46,47]$. The same observation has been made with ER $\beta$, with receptor invalidation inducing delayed puberty and a decrease in the number of kisspeptinpositive cells in RP3V at postnatal day 25 [48]. This population of kisspeptin neurons appears to be in- 


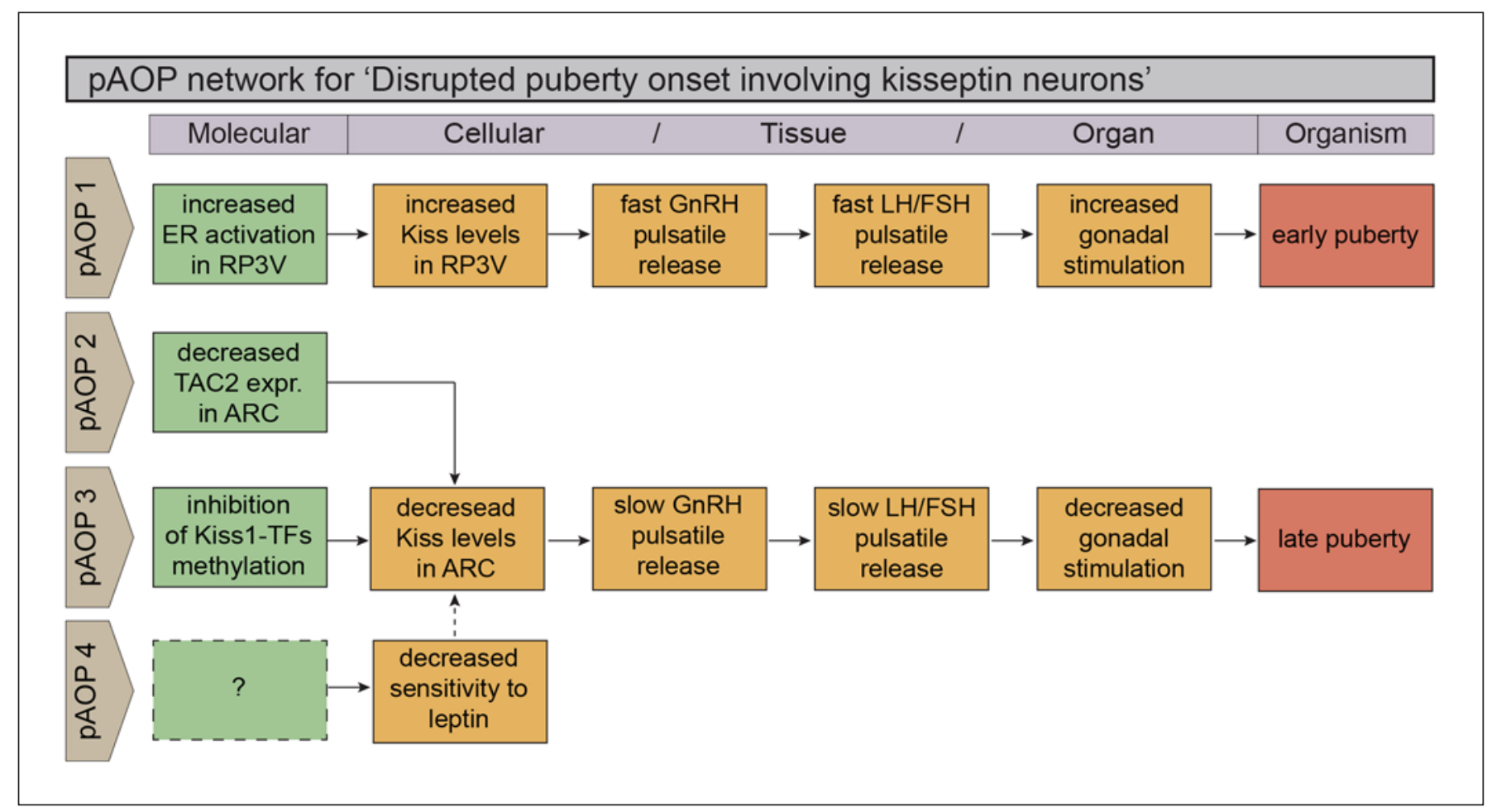

Fig. 3. pAOP network for disrupted puberty onset involving kisspeptin neurons. Pulsatile GnRH release increases to its maximum frequency at puberty when it induces a rise in $\mathrm{LH}$ and $\mathrm{FSH}$, ultimately leading to gonadal maturation. Kisspeptin neurons, located in the RP3V and ARC, are a major activator of GnRH release. Disruption of pubertal timing could occur after a modification of kisspeptin level due to pAOP-1: an increased activation of ER in RP3V; pAOP-2: a decreased TAC2 expression in ARC;

volved in the last step of puberty onset, to stimulate the first LH surge to induce the first ovulation and complete puberty [49].

\section{Evidence for Chemical Triggers}

Many chemicals are able to bind to and activate ER [50], and among them several are suspected to induce early puberty [3]. Initial publications measuring Kiss1 expression in the whole hypothalamus without discriminating the 2 key populations observed either an increase [51] or a decrease $[52,53]$ after early exposure to ER modulators BPA or DES. More recent studies have observed an increase in RP3V kisspeptin expression after perinatal BPA exposure [54-56]; two of them linked this increase with a disruption of pubertal timing $[54,55]$. Despite a similar effect on kisspeptin expression, the effects on vaginal opening were opposite. Perinatal exposure to BPA 5 $\mu \mathrm{g} / \mathrm{kg} /$ day was associated with early puberty [55] while
pAOP-3: an inhibition of the methylation of Kiss1 TFs; or pAOP4: a decreased sensitivity to leptin. pAOP, putative adverse outcome pathway; $\mathrm{GnRH}$, gonadotropin-releasing hormone; $\mathrm{LH}$, luteinizing hormone; FSH, follicle-stimulating hormone; RP3V, rostral periventricular area of the third ventricle; ARC, arcuate nucleus; ER, estrogen receptor; TF, transcription factors; TAC2, tachykinin 2. maternal exposure to a higher dose (BPA $50 \mu \mathrm{g} / \mathrm{kg} /$ day) was associated with a delay [54]. It is also notable that Patisaul et al. [57] did not see any modification in kisspeptin immunoreactivity in the anterior ventral periventricular nucleus after neonatal exposure to the same high BPA dose $(50 \mu \mathrm{g} / \mathrm{kg} /$ day $)$. The same group reported also an advance of vaginal opening after neonatal exposure to another EDC, the phytoestrogen genistein, but this early puberty was associated with a decrease in kisspeptin fiber density in the anterior ventral periventricular nucleus [58]. More studies reporting the impact of EDC exposure on kisspeptin expression in RP3V are reviewed by LopezRodriguez et al. [59]. As reported by Parent et al. [3], several publications show that pubertal effects vary with timing or doses of exposure. However, all indicate that modifications of ER activation or kisspeptin level in RP3V are associated with changes in puberty onset in both directions. 
pAOP-2: "Decrease of TAC2 in ARC Leads to a

Delay of Puberty"

This pAOP proposes to link a decrease in tachykinin 2 (TAC2) gene expression in the ARC to delayed puberty via a reduction of kisspeptin stimulation (shown in Fig. 3).

\section{Supporting Evidence}

In the ARC, kisspeptins are mainly expressed by KNDy neurons. These neurons coexpress kisspeptin, neurokinin $B(\mathrm{NKB})$, and dynorphin (DYN). This population is critical for puberty onset. As for Kiss 1 and Kiss1R mutations, the loss-of-function mutations in TAC3 (coding for $\mathrm{NKB}$ in human) or TACR3 (coding for its receptor) cause pubertal failure and hypogonadotropic hypogonadism in humans $[60,61]$. In female rats, the inhibition of DYN signaling by the administration of its receptor antagonist leads to early puberty [62]. Thus, NKB and DYN appear to exert a reciprocal modulation of kisspeptin release, which is critical for GnRH secretion modulation. Using GCaMP6 fiber photometry technology, the Herbison lab recently demonstrated the crucial role of ARC kisspeptin neurons by showing that those neurons show a rhythmic increase in intracellular calcium corresponding to LH release [63].

\section{Evidence for Chemical Triggers}

The expression of Kiss 1 and Tac2 in the ARC is sensitive to early stress such as undernutrition or high-fat diet [64-66]. Early exposure to EDCs also leads to modifications of Kiss 1 expression in the ARC, although the resulting effects depend on the nature, dose, and period of exposure. Neonatal exposure to dibutyl phthalate (0.5-50 mg/kg/day) increases Kiss $1 \mathrm{mRNA}$ and kisspeptin immunoreactivity in the ARC and leads to advanced puberty in female rats [67] while exposure to genistein $(10 \mathrm{mg} / \mathrm{kg} /$ day $)$ during the first 3 days of life leads to a decrease in kisspeptin immunoreactive fibers in the ARC and to advanced vaginal opening [68]. Recently, Ruiz-Pino et al. [55] have shown by in situ hybridization that the expression of both Kiss1 and Tac2 in the ARC decreases after perinatal exposure to a low dose of BPA ( $5 \mu \mathrm{g} / \mathrm{kg} /$ day) in mice. This decrease was, however, associated with early onset of puberty but a decrease in LH level [55]. Those examples illustrate the sensitivity of the KNDy system to EDC exposure even if the consequences can vary depending on the dose or period of exposure.

Putative AOP Networks for Disrupted Female Pubertal Onset
pAOP-3: "Inhibition of the Methylation of Kiss1

Transcriptional Regulators Leads to a Delay of

Puberty"

This pAOP proposes to link an inhibition of the methylation of Kiss1 transcriptional regulators to delayed puberty via a reduction in kisspeptin expression (shown in Fig. 3).

\section{Supporting Evidence}

Transgenic mouse harboring mutations in KISS1 or in KISS1R genes [69] or prepubertal rats treated with an effective kisspeptin antagonist [70] fail to undergo pubertal maturation on time, indicating the importance of kisspeptin in pubertal timing. Our understanding of the molecular mechanisms responsible for the precise timing of puberty has expanded recently, due in part to the recognition of the role of epigenetic mechanisms in the control of normal pubertal maturation. It is now clearly established that a switch from epigenetic repression to activation within kisspeptin neurons in the ARC is a core mechanism underlying the initiation of female puberty [ 71 , 72]. The transcriptional activity of activating genes such as Kiss 1 is repressed by silencing molecules, epitomized by the polycomb (PcG) complex. PcG proteins catalyze the deposition of histone PTMs associated with gene silencing at key regulatory regions. As puberty approaches, these $\mathrm{PcG}$ proteins are evicted from promoter regions controlling puberty-activating genes in the ARC, and as a result of this loss, the content of histone repressive marks is reduced $[73,74]$. This hypothesis has been confirmed by the administration of an inhibitor of DNA methylation which delays puberty in female rats and is associated with the absence of decreased expression of the transcriptional repressors Eed and Cbx7 [74].

\section{Evidence for Chemical Triggers}

Several studies have shown that exposure to EDCs can modify DNA methyl-transferase expression in the brain [75-78]. In addition, hypothalamic methylation of Esr1, coding for ERalpha, is increased at puberty after gestational exposure to BPA [76]. Recently, other early stresses such as subnutrition have been shown to delay puberty through an increase in Sirt1 and decrease in Kiss1 expression in the ARC. Sirt1 is an epigenetic enzyme which induces histone deacetylation and heterochromatin formation to downregulate gene expression [79]. No study has so far documented direct effect of EDCs on the epigenetic control of Kiss 1 expression and puberty onset, but the data described above suggest that this is a likely mechanism. 


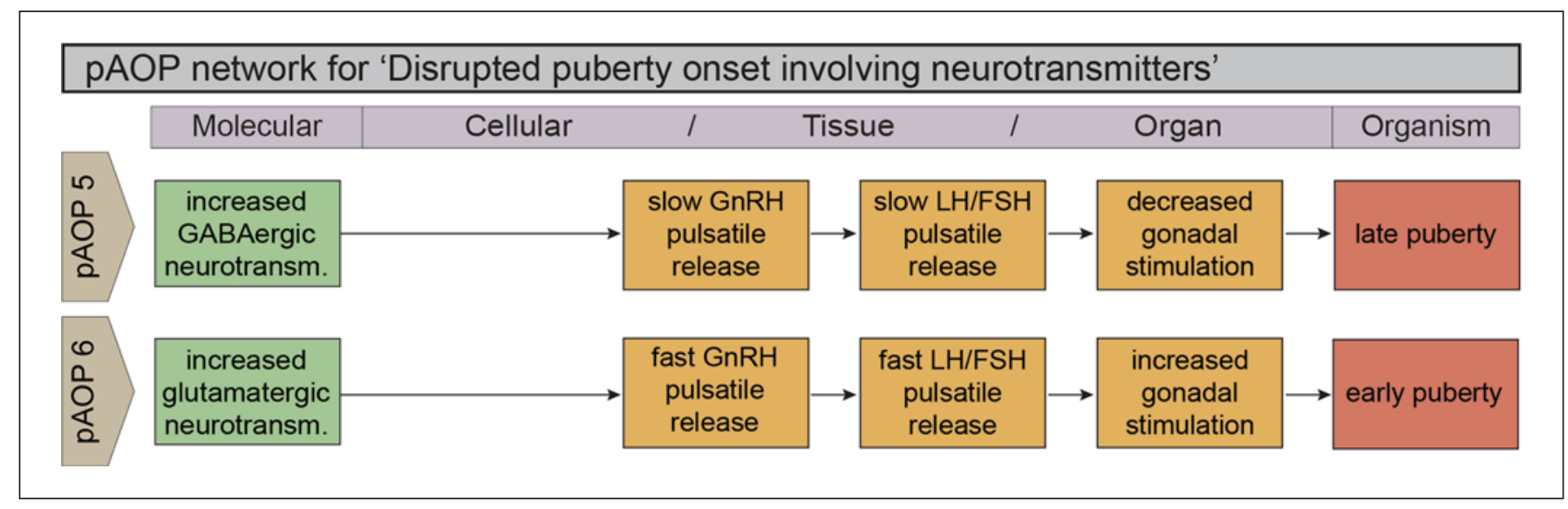

Fig. 4. pAOP network for disrupted onset involving neurotransmitters. The pubertal increase in $\mathrm{GnRH}$ release inducing the rise of LH/FSH and gonadal stimulation is under the control of excitatory and inhibitory neurotransmitters. In the hypothalamus, an increase in GABAergic neurotransmission can lead to a delayed

pAOP-4: "Decreased Leptin Sensitivity Leads to Late Puberty in Females"

This $\mathrm{pAOP}$ proposes to link reduced hypothalamic sensitivity to leptin with delayed puberty via an indirect reduction of kisspeptin stimulation in the ARC (shown in Fig. 3).

\section{Supporting Evidence}

Leptin is produced by adipose tissue in direct proportion with body fat content. It informs the central nervous system about the status of fat stores and exerts anorectic effects [80]. Leptin-deficient mice develop obesity, but also an absence of puberty and infertility [81, 82]. If food availability is limited, these mice have normal weight but infertility remains and can only be corrected by administration of leptin $[83,84]$. Leptin, therefore, appears to be a necessary factor for the initiation of puberty, evidenced by its ability to induce GnRH secretion ex vivo from the prepubertal rat hypothalamus [85]. Indeed, intraperitoneal injection of leptin in 15-day-old female rats results in an acceleration of GnRH pulsatile release [85], but leptin does not act directly on GnRH neurons [86]. Kisspeptin level is particularly sensitive to changes in metabolic and nutritional cues, and its expression follows leptin levels. A reduction in leptin level is associated with an inhibition of Kiss1 expression while leptin administration increases Kiss1 gene transcription [87]. Recent data indicate that interaction with PACAP neurons, expressing pituitary adenylate cyclase activating polypeptide, in the ventral premammillary nucleus (PMV) and making direct contact with kisspeptin neurons, could be the path- puberty (pAOP-5) while an increase of glutamatergic neurotransmission can induce an early puberty (pAOP-6). pAOP, putative adverse outcome pathway; GnRH, gonadotropin-releasing hormone; $\mathrm{LH}$, luteinizing hormone; $\mathrm{FSH}$, follicle-stimulating hormone.

way explaining leptin action on the hypothalamus for puberty control [88]. The deletion of this population in PMV causes delayed puberty, and PMV is a relevant site of leptin action as activating leptin signalization in PMV restores puberty in leptin-deficient mice [89]. Other intermediary neurons have been proposed to convey leptin signals such as GABAergic neurons [90], nitric oxide neurons [91], or POMC neurons [92].

\section{Evidence for Chemical Triggers}

Decreased hypothalamic sensitivity to leptin is observed in food restricted [53, 93], but also in obese rats [94]. Early-life exposure to DES or BPA increases leptin levels in rodents $[53,95,96]$. In addition, the stimulatory effect of leptin on GnRH secretion is diminished both by early postnatal exposure to DES and by prenatal nutritional restriction. In a rat model using combined prenatal dietary restriction and postnatal DES exposure, the stimulating effect of leptin on GnRH secretion is completely obliterated [53]. Thus, developmental exposure to EDCs appears to affect GnRH response to the hypothalamic action of leptin. However, intermediary neurons mediating this action remain to be identified.

\section{pAOPs Involving Neurotransmitters}

pAOP-5: "Elevated GABA Leads to Late Puberty in

Females"

This AOP proposes to link increased hypothalamic GABAergic neurotransmission to delayed puberty in girls (shown in Fig. 4). 


\section{Supporting Evidence}

Even though GABA ( $\gamma$-aminobutyric acid) direct action on GnRH neurons seems excitatory, the global effect of GABA on the GnRH network is inhibitory [97]. GABA levels in the preoptic area of the hypothalamus decrease just before puberty [98], and the inhibitory effect of GABA on pulsatile GnRH secretion is relatively higher between days 5 and 15 postnatally but decreases at puberty in the rodent [99-101]. This decrease in GABAergic input is crucial for the reactivation of GnRH release at puberty.

\section{Evidence for Chemical Triggers}

GABA action on GnRH neurons can be modulated by environmental/peripheral inputs, such as metabolic or steroidal status or EDC exposure. For instance, the frequency of spontaneous GABAergic postsynaptic currents in $\mathrm{GnRH}$ neurons and $\mathrm{GnRH}$ neuronal activity is decreased by acute fasting $[102,103]$. GABAergic transmission is also regulated by estradiol and progesterone. ER $\alpha$ agonists reduce GABA transmission frequency to GnRH neurons $[104,105]$ while progesterone is an allosteric agonist of the GABA A receptor [103]. Early exposure to EDCs such as BPA can lead to increased [106$108]$ or decreased $[77,106,109,110]$ GABAergic neurotransmission depending on the dose and the timing of exposure. Gestational exposure to BPA leads to increased GABA release associated with decreased GnRH and testosterone release in male rats [107]. Postnatal exposure to a very low dose of BPA led to delayed puberty associated with higher hypothalamic GABAergic tone and slower GnRH pulsatile release [111]. Recently, children (from 7 to 12 years old) living near a ferromanganese alloy plant in Brazil have been reported to develop early onset of puberty [112]. A translational study in rats showed that exposure to manganese stimulates $\mathrm{GnRH}$ release and advances puberty onset decreasing GABA A receptor signaling in the preoptic area [113]. All these pieces of evidence show that the GABAergic pathway is influenced by environmental inputs, including chemical compounds that can disturb GnRH release and pubertal timing.

pAOP-6: "Elevated Glutamate Leads to Early Puberty in Females"

This AOP proposes to link increased hypothalamic glutamatergic neurotransmission to advanced puberty in girls (shown in Fig. 4).
Supporting Evidence

Glutamate concentration increases in the hypothalamus throughout postnatal development until puberty [98]. Its NMDA receptors appear to play an important role in the regulation of $\mathrm{GnRH}$ secretion and the initiation of puberty. Intermittent administration of NMDA, in a pulsatile mode, can induce early puberty in monkeys [114] and in rats $[115,116]$. Similarly, administration of specific NMDA receptor antagonists delays the onset of puberty $[117,118]$ and inhibits LH secretion in vivo [119, $120]$ and GnRH secretion in vitro [121].

\section{Evidence for Chemical Triggers}

Several studies indicate an impact of EDCs on glutamatergic signalization in the brain [122-124] but very few have focused on the hypothalamic GnRH network. In adult females, Aroclor 1221, a PCB mix, decreases NMDA-NR2b subunit mRNA expression in the preoptic area [125]. In female rats, neonatal exposure to dichlorodiphenyltrichloroethane, an estrogenic insecticide, induces early puberty and increases glutamate-evoked GnRH release. This last effect involves AMPA, estrogen, and androgen receptors [126, 127]. A decrease in glutamate and in GnRH release was observed in prepubertal male rats after perinatal exposure to BPA [128]. While more investigations in this field are required, these first pieces of evidence suggest an impact of EDCs on the glutamatergic pathway regulating $\mathrm{GnRH}$ release.

\section{Potential for Test Method Development}

The AOP concept implies that improved speed and accuracy of chemical testing can be achieved by relying more on alternative test methods than on animal testing or on improving current in vivo test methods by including new and very sensitive endpoints. Currently, in vivo toxicity test guidelines established by OECD include examination of puberty timing by assessing age at vaginal opening in females and preputial separation in males, as well as the weight of the gonads [38]. More sensitive targets could be examined. Puberty timing serves as an AO in putative AOPs identified here. The identification of KEs that are measurable in vivo or in vitro would open up for opportunities to predict adverse effects on puberty timing. Puberty is induced by an increase in GnRH pulsatile release. Hypothalamic explants obtained from female rats have the particularity to release $\mathrm{GnRH}$ in the incubation medium in a pulsatile pattern similar to what is reported in vivo [13]. Changes in pulsatile GnRH secre- 
tion ex vivo appear to be particularly sensitive to EDC exposure $[53,111,126,129]$ and represent a KE to detect or predict disruption of puberty. This technique is nevertheless challenging to perform in large scale. A new tool, the development of $\mathrm{GnRH}$-secreting neurons from human pluripotent stem cells $[130,131]$, could be relevant in the future to perform this kind of analysis, but these new cells require further characterization of their pulsatile secretory properties. However, the changes in $\mathrm{GnRH}$ release are often the consequences of the disruption of $\mathrm{GnRH}$ regulators.

As described in this review, we see a potential for test assay development in relation to KEs associated with kisspeptins and GABA/glutamate. The level of expression of those key hypothalamic factors using transcriptomic (RNAsequencing and RT-qPCR) or proteomic (Western blot and immunohistochemistry) analysis after early in vivo exposure could help identify chemicals that disrupt puberty. Specific in vitro assays need also to be developed to reduce or avoid animal use and to supplement OECD in vitro test guidelines. Currently, only the identified KE "increased activity of ER" is included in these guidelines. The activity of kisspeptin or GABA/ glutamate promotors can be studied by gene reporter assay. Using this technique, Heger et al. $[53,132]$ have previously shown that the kisspeptin promotor is sensitive to BPA and DES. In addition, rodent hypothalamic primary cell culture [132], specific immortalized hypothalamic cell lines [133], hypothalamic neurons generated from human pluripotent stem cells [134], or new models of complex neuronal cocultures [135] could be developed as a tool to determine the impact of EDC on the expression of a specific target such as kisspeptin or GABA/glutamate.

\section{Concluding Remarks}

Puberty is a critical step towards reproductive maturity and health, and altered pubertal timing is associated with an increased risk of pathologies later in life [136139]. Herein, we have proposed 6 AOPs that can help explain, at the mechanistic level, how EDCs disturb puberty onset. The difficulty of building AOPs relevant to disturbed puberty lies in the fact that the hypothalamic control of puberty is still incompletely understood. Many knowledge gaps persist regarding the specific role of the 2 populations of kisspeptin neurons, the leptin targets in the hypothalamus, and the epigenetic regulation of $\mathrm{GnRH}$ neuron activity. Our 6 pAOPs focus only on identified
EDC targets. For instance, kisspeptin neurons are also regulated by metabolic sensors (such as mTor and AMPK) [140], other hypothalamic neurons (as POMC-AgRP neurons) [66], or specific protein such as Makorin ring finger protein 3 [141, 142], but which have yet to be described as EDC targets. Along the same line, other epigenetic mechanisms regulating puberty have recently been identified (miRNA and tritorax group) [143, 144], but their sensitivity to EDCs remains to be studied. GnRH neuron migration has been suggested to be affected by EDCs $[145,146]$, but more investigations are needed to confirm this theory and to build an AOP. In addition, the HPG axis that regulates puberty onset is influenced by gonadal feedback while gonads are themselves targets of EDCs. This latter aspect was not discussed here as a large review of putative ovarian AOPs has been published recently [147]. Nevertheless, the development of our 6 pAOPs has underlined KEs that can detect or predict disruption of puberty: pulsatile GnRH release and hypothalamic expression of kisspeptin and of GABA/glutamate. Those factors can be considered as good biomarkers for in vivo or in vitro test methods. Based on these data, it is now time to develop robust alternative test assays to help safeguard female reproductive health.

\section{Conflict of Interest Statement}

The authors have no conflicts of interest to declare.

\section{Funding Sources}

This project has received funding from the European Union's Horizon 2020 research and innovation program under grant agreement No. 825100

\section{Author Contributions}

D. Franssen, A.-S. Parent, and T. Svingen wrote the manuscript; J. Boberg, D. Lopez Rodriguez, and Majorie Van Duursen critically reviewed the manuscript. All authors have read and agreed to the submitted version of the manuscript.

References

1 Tanner J. Growth at adolescence. Blakwell S. Oxford; 1962.

2 Parent A-SS, Teilmann G, Juul A, Skakkebaek NE, Toppari J, Bourguignon J-PJP. The timing of normal puberty and the age limits of sexual precocity: variations around the world, secular trends, and changes after migration. Endocr Rev. 2003 Oct;24(5):668-93. 
3 Parent AS, Franssen D, Fudvoye J, Gérard A, Bourguignon JP. Developmental variations in environmental influences including endocrine disruptors on pubertal timing and neuroendocrine control: revision of human observations and mechanistic insight from rodents. Front Neuroendocrinol. 2015;38: 12-36.

$4 \mathrm{Zhu}$ J, Chan YM. Adult consequences of selflimited delayed puberty. Pediatrics. 2017; 139(6):e20163177.

5 Day FR, Thompson DJ, Helgason H, Chasman DI, Finucane H, Sulem P, et al. Genomic analyses identify hundreds of variants associated with age at menarche and support a role for puberty timing in cancer risk. Nat Genet. 2017;49(6):834-41.

6 Cheng TS, Day FR, Lakshman R, Ong KK. Association of puberty timing with type 2 diabetes: a systematic review and meta analysis. PLoS Med. 2020 Jan 6;17(1):e1003017.

7 Mendle J, Ryan RM, McKone KMP. Age at menarche, depression, and antisocial behavior in adulthood. Pediatrics. 2018 Jan;141(1): e20171703.

8 Johansson HKL, Svingen T, Fowler PA, Vinggaard AM, Boberg J. Environmental influences on ovarian dysgenesis: developmental windows sensitive to chemical exposures. Nat Rev Endocrinol. 2017;13(7):400-14.

9 Plant TM, Zeleznik AJ, editors. Knobil and Neill's physiology of reproduction. 4th ed. 2015.

10 Becú-Villalobos D, González Iglesias A, DíazTorga G, Hockl P, Libertun C. Brain sexual differentiation and gonadotropins secretion in the rat. Cell Mol Neurobiol. 1997;17(6): 699-715.

11 Harris GC, Levine JE. Pubertal acceleration of pulsatile gonadotropin-releasing hormone release in male rats as revealed by microdialysis. Endocrinology. 2003;144(1):163-71.

12 Sisk CL, Richardson HN, Chappell PE, Levine JE, Program N. In vivo gonadotropin-releasing hormone secretion in female rats during peripubertal development and on proestrus. Endocrinology. 2001;142(7):2929-36.

13 Bourguignon JP, Franchimont P. Puberty-related increase in episodic LHRH release from rat hypothalamus in vitro. Endocrinology. 1984;114(5):1941-3.

14 Ojeda, Skinner MK. Chapter 38. Puberty in the rat. In: Knobil E, Neill JD, editors. Knobil and Neill's physiology of reproduction. Gulf Professional Publishing; 2006. Vol. 2; p. 2061-103.

15 Caron E, Ciofi P, Prevot V, Bouret SG. Alteration in neonatal nutrition causes perturbations in hypothalamic neural circuits controlling reproductive function. J Neurosci. 2012;32(33):11486-94.

16 Messina A, Langlet F, Chachlaki K, Roa J, Rasika S, Jouy N, et al. A microRNA switch regulates the rise in hypothalamic GnRH production before puberty. Nat Neurosci. 2016; 19(6):835-44.
17 Parent AS, Teilmann G, Juul A, Skakkebaek NE, Toppari J, Bourguignon JP. The timing of normal puberty and the age limits of sexual precocity: variations around the world, secular trends, and changes after migration. Endocr Rev. 2003 Oct;24(5):668-93.

18 Aksglaede L, Sørensen K, Petersen JH, Skakkebaek NE, Juul A. Recent decline in age at breast development: the Copenhagen puberty study. Pediatrics. 2009;123(5):e932.

19 Euling SY, Herman-Giddens ME, Lee PA, Selevan SG, Juul A, Sørensen TI, et al. Examination of US puberty-timing data from 1940 to 1994 for secular trends: panel findings. Pediatrics. 2008;121(Suppl 3):S172.

20 Biro FM, Greenspan LC, Galvez MP, Pinney SM, Teitelbaum S, Windham GC, et al. Onset of breast development in a longitudinal cohort. Pediatrics. 2013;132(6):1019-27.

21 Fudvoye J, Lopez-Rodriguez D, Franssen D, Parent AS. Endocrine disrupters and possible contribution to pubertal changes. Best Pract Res Clin Endocrinol Metab. 2019;33(3): 101300.

22 Lamb JC, Boffetta P, Foster WG, Goodman JE, Hentz KL, Rhomberg LR, et al. Critical comments on the WHO-UNEP State of the Science of Endocrine Disrupting Chemicals: 2012. Regul Toxicol Pharmacol. 2014;69(1): 22-40.

23 Bergman A, Heindel JJ, Kasten T, Kidd KA, Jobling S, Neira M, et al. The impact of endocrine disruption: a consensus statement on the state of the science. Environ Health Perspect. 2013;121(4):A104-6.

$24 \mathrm{WHO} / \mathrm{UNEP}$. Global assessment of the stateof-the-science of endocrine disruptors. In: Damstra T, Barlow S, Bergman A, Kavlock R, Van Der Kraakeds G, editors. 2013.

25 Wohlfahrt-Veje C, Andersen HR, Schmidt IM, Aksglaede L, Sørensen K, Juul A, et al. Early breast development in girls after prenatal exposure to non-persistent pesticides. Int $\mathrm{J}$ Androl. 2012;35(3):273-82.

26 Marks KJ, Hartman TJ, Taylor EV, Rybak ME, Northstone K, Marcus M. Exposure to phytoestrogens in utero and age at menarche in a contemporary British cohort. Environ Res. 2017;155:287-93.

27 Adgent MA, Daniels JL, Rogan WJ, Adair L, Edwards LJ, Westreich D, et al. Early-life soy exposure and age at menarche. Paediatr Perinat Epidemiol. 2012 Mar;26(2):163-75.

28 Strom BL, Schinnar R, Ziegler EE, Barnhart KT, Sammel MD, Macones GA, et al. Exposure to soy-based formula in infancy and endocrinological and reproductive outcomes in young adulthood. JAMA. 2001;286(7):80714.

29 Harley KG, Rauch SA, Chevrier J, Kogut K, Parra KL, Trujillo C, et al. Association of prenatal and childhood PBDE exposure with timing of puberty in boys and girls. Environ Int. 2017;100:132-8.
30 Windham GC, Pinney SM, Voss RW, Sjödin A, Biro FM, Greenspan LC, et al. Brominated flame retardants and other persistent organohalogenated compounds in relation to timing of puberty in a longitudinal study of girls. Environ Health Perspect. 2015 Oct;123(10): 1046-52.

31 Chen A, Chung E, DeFranco EA, Pinney SM, Dietrich KN. Serum PBDEs and age at menarche in adolescent girls: analysis of the $\mathrm{Na}$ tional Health and Nutrition Examination Survey 2003-2004. Environ Res. 2011;111(6): 831-7.

32 van Duursen MBM, Boberg J, Christiansen S, Connolly L, Damdimopoulou P, Filis P, et al. Safeguarding female reproductive health against endocrine disrupting chemicals: the FREIA project. Int J Mol Sci. 2020;21(9):3215.

33 Johansson HKL, Damdimopoulou P, van Duursen MBM, Boberg J, Franssen D, de Cock M, et al. Putative adverse outcome pathways for female reproductive disorders to improve testing and regulation of chemicals. Arch Toxicol. 2020 Oct;94(10):3359-79.

34 Villeneuve DL, Crump D, Garcia-Reyero N, Hecker M, Hutchinson TH, LaLone CA, et al. Adverse outcome pathway development II: best practices. Toxicol Sci. 2014;142(2):32130.

35 Draskau MK, Spiller CM, Boberg J, Bowles J, Svingen T. Developmental biology meets toxicology: contributing reproductive mechanisms to build adverse outcome pathways Mol Hum Reprod. 2020 Jan;26(2):111-6.

36 Krewski D, Acosta D Jr, Andersen M, Anderson $\mathrm{H}$, Bailar JC 3rd, Boekelheide $\mathrm{K}$, et al. Toxicity testing in the 21st century: a vision and a strategy. J Toxicol Environ Health B Crit Rev. 2010;13(2-4):51-138.

37 Ankley GT, Edwards SW. The adverse outcome pathway: a multifaceted framework supporting 21st century toxicology. Curr Opin Toxicol. 2018;9:1-7.

38 OECD. Users' handbook supplement to the guidance document for developing and assessing adverse outcome pathways. 2016

39 Knapen D, Vergauwen L, Villeneuve DL, Ankley GT. The potential of AOP networks for reproductive and developmental toxicity assay development. Reprod Toxicol. 2015;56: 52-5.

40 Seminara SB, Messager S, Chatzidaki EE, Thresher RR, Acierno JS, Shagoury JK, et al. The GPR54 gene as a regulator of puberty. N Engl J Med. 2003 Oct;349(17):1614-27.

41 de Roux N, Genin E, Carel JC, Matsuda F, Chaussain JL, Milgrom E. Hypogonadotropic hypogonadism due to loss of function of the KiSS1-derived peptide receptor GPR54. Proc Natl Acad Sci U S A. 2003 Sep;100(19):109726.

42 García-Galiano D, Pinilla L, Tena-Sempere M. Sex steroids and the control of the Kiss 1 system: developmental roles and major regulatory actions. J Neuroendocrinol. 2012 Jan; $24(1): 22-33$ 
43 Clarkson J, Herbison AE. Postnatal development of kisspeptin neurons in mouse hypothalamus; sexual dimorphism and projections to gonadotropin-releasing hormone neurons. Endocrinology. 2006;147(12):5817-25.

44 Navarro VM, Castellano JM, FernándezFernández R, Barreiro ML, Roa J, SanchezCriado JE, et al. Developmental and hormonally regulated messenger ribonucleic acid expression of KiSS-1 and its putative receptor, GPR54, in rat hypothalamus and potent luteinizing hormone-releasing activity of KiSS1 peptide. Endocrinology. 2004 Oct;145(10): 4565-74.

45 Semaan SJ, Kauffman AS. Daily successive changes in reproductive gene expression and neuronal activation in the brains of pubertal female mice. Mol Cell Endocrinol. 2015;401: 84-97.

46 Clarkson J, Boon WC, Simpson ER, Herbison AE. Postnatal development of an estradiolkisspeptin positive feedback mechanism implicated in puberty onset. Endocrinology. 2009; 150(7):3214-20.

47 Mayer C, Acosta-Martinez M, Dubois SL, Wolfe A, Radovick S, Boehm U, et al. Timing and completion of puberty in female mice depend on estrogen receptor alpha-signaling in kisspeptin neurons. Proc Natl Acad Sci U S A. 2010;107(52):22693-8.

48 Naulé L, Robert V, Parmentier C, Martini M, Keller M, Cohen-Solal M, et al. Delayed pubertal onset and prepubertal Kiss1 expression in female mice lacking central oestrogen receptor beta. Hum Mol Genet. 2015;24(25): 7326-38.

49 Herbison AE. Control of puberty onset and fertility by gonadotropin-releasing hormone neurons. Nat Rev Endocrinol. 2016;12(8): $452-66$.

50 Diamanti-Kandarakis E, Bourguignon JP, Giudice LC, Hauser R, Prins GS, Soto AM, et al. Endocrine-disrupting chemicals: an endocrine society scientific statement. Endocr Rev. 2009;30(4):293-342.

51 Xi W, Lee CK, Yeung WS, Giesy JP, Wong $\mathrm{MH}$, Zhang $\mathrm{X}$, et al. Effect of perinatal and postnatal bisphenol A exposure to the regulatory circuits at the hypothalamus-pituitarygonadal axis of CD-1 mice. Reprod Toxicol. 2011;31(4):409-17.

52 Navarro VM, Sánchez-Garrido MA, Castellano JM, Roa J, García-Galiano D, Pineda R, et al. Persistent impairment of hypothalamic KiSS-1 system after exposures to estrogenic compounds at critical periods of brain sex differentiation. Endocrinology. 2009; 150(5): 2359-67.

53 Franssen D, Ioannou YS, Alvarez-real A, Gerard A, Mueller JK, Heger S, et al. Pubertal timing after neonatal diethylstilbestrol exposure in female rats: neuroendocrine vs peripheral effects and additive role of prenatal food restriction. Reprod Toxicol. 2014;44:6372.
54 Naulé L, Picot M, Martini M, Parmentier C, Hardin-Pouzet H, Keller M, et al. Neuroendocrine and behavioral effects of maternal exposure to oral bisphenol A in female mice. J Endocrinol. 2014;220(3):375-88.

55 Ruiz-Pino F, Miceli D, Franssen D, Vazquez MJ, Farinetti A, Castellano JM, et al. Environmentally relevant perinatal exposures to bisphenol A disrupt postnatal Kiss1/NKB neuronal maturation and puberty onset in female mice. Environ Health Perspect. 2019 Oct; 127(10):107011.

56 Wang X, Chang F, Bai Y, Chen F, Zhang J, Chen L. Bisphenol A enhances kisspeptin neurons in anteroventral periventricular nucleus of female mice. J Endocrinol. 2014; 221(2):201-13.

57 Patisaul HB, Todd KL, Mickens JA, Adewale HB. Impact of neonatal exposure to the ERalpha agonist PPT, bisphenol-A or phytoestrogens on hypothalamic kisspeptin fiber density in male and female rats. Neurotoxicology. 2009;30(3):350-7.

58 Bateman HL, Patisaul HB. Disrupted female reproductive physiology following neonatal exposure to phytoestrogens or estrogen specific ligands is associated with decreased GnRH activation and kisspeptin fiber density in the hypothalamus. Neurotoxicology. 2008 Nov;29(6):988-97.

59 Lopez-Rodriguez D, Franssen D, Bakker J, Lomniczi A, Parent AS. Cellular and molecular features of EDC exposure: consequences for the GnRH network. Nat Rev Endocrinol. $2021 \mathrm{Feb} ; 17(3): 83-96$

60 Topaloglu AK, Reimann F, Guclu M, Yalin AS, Kotan LD, Porter KM, et al. TAC3 and TACR3 mutations in familial hypogonadotropic hypogonadism reveal a key role for Neurokinin B in the central control of reproduction. Nat Genet. 2009 Mar;41(3):354-8.

61 Guran T, Tolhurst G, Bereket A, Rocha N, Porter K, Turan S, et al. Hypogonadotropic hypogonadism due to a novel missense mutation in the first extracellular loop of the neurokinin B receptor. J Clin Endocrinol Metab. 2009;94(10):3633-9.

62 Nakahara T, Uenoyama Y, Iwase A, Oishi S, Nakamura S, Minabe S, et al. Chronic peripheral administration of kappa-opioid receptor antagonist advances puberty onset associated with acceleration of pulsatile luteinizing hormone secretion in female rats. J Reprod Dev. 2013;59(5):479-84.

63 Clarkson J, Han SY, Piet R, McLennan T, Kane GM, Ng J, et al. Definition of the hypothalamic GnRH pulse generator in mice. Proc Natl Acad Sci U S A. 2017 Nov;114(47): E10216-23.

64 Castellano JM, Bentsen AH, Sánchez-Garrido MA, Ruiz-Pino F, Romero M, Garcia-Galiano $\mathrm{D}$, et al. Early metabolic programming of puberty onset: impact of changes in postnatal feeding and rearing conditions on the timing of puberty and development of the hypothalamic kisspeptin system. Endocrinology. 2011 Sep;152(9):3396-408.
65 Navarro VM, Tena-Sempere M. Neuroendocrine control by kisspeptins: role in metabolic regulation of fertility. Nat Rev Endocrinol. 2012 Jan;8(1):40-53.

66 Navarro VM. Metabolic regulation of kisspeptin: the link between energy balance and reproduction. Nat Rev Endocrinol. 2020 16(8):407-20.

67 Hu J, Du G, Zhang W, Huang H, Chen D, Wu $\mathrm{D}$, et al. Short-term neonatal/prepubertal exposure of dibutyl phthalate (DBP) advanced pubertal timing and affected hypothalamic kisspeptin/GPR54 expression differently in female rats. Toxicology. 2013;314(1):65-75

68 Losa SM, Todd KL, Sullivan AW, Cao J, Mickens JA, Patisaul HB. Neonatal exposure to genistein adversely impacts the ontogeny of hypothalamic kisspeptin signaling pathways and ovarian development in the peripubertal female rat. Reprod Toxicol. 2011;31(3):2809.

69 Colledge WH. Transgenic mouse models to study Gpr54/kisspeptin physiology. Peptides. 2009 Jan;30(1):34-41.

70 Pineda R, Garcia-Galiano D, Roseweir A, Romero M, Sanchez-Garrido MA, Ruiz-Pino $\mathrm{F}$, et al. Critical roles of kisspeptins in female puberty and preovulatory gonadotropin surges as revealed by a novel antagonist. Endocrinology. 2010;151(2):722-30.

71 Lomniczi A, Loche A, Castellano JM, Ronnekleiv OK, Bosch M, Kaidar G, et al. Epigenetic control of female puberty. Nat Neurosci. 2013 Mar; 16(3):281-9.

72 Aylwin CF, Vigh-Conrad K, Lomniczi A, Aylwin CF, Vigh-Conrad K. The emerging role of chromatin remodeling factors in female pubertal development. Neuroendocrinology. 2019 Feb;109(3):208-17.

73 Ojeda SR, Lomniczi A, Sandau U, Matagne V. New concepts on the control of the onset of puberty. Endocr Dev. 2010;17:44-51.

74 Lomniczi A, Wright $\mathrm{H}$, Castellano JM, Matagne V, Toro CA, Ramaswamy S, et al. Epigenetic regulation of puberty via Zinc finger protein-mediated transcriptional repression. Nat Commun. 2015;6(1):10195.

75 Kumar D, Thakur MK. Effect of perinatal exposure to Bisphenol-A on DNA methylation and histone acetylation in cerebral cortex and hippocampus of postnatal male mice. J Toxicol Sci. 2017;42(3):281-9.

76 Kundakovic M, Gudsnuk K, Franks B, Madrid J, Miller RL, Perera FP, et al. Sex-specific epigenetic disruption and behavioral changes following low-dose in utero bisphenol A exposure. Proc Natl Acad Sci U S A. 2013; 110(24):9956-61.

77 Zhou R, Chen F, Chang F, Bai Y, Chen L. Persistent overexpression of DNA methyltransferase 1 attenuating GABAergic inhibition in basolateral amygdala accounts for anxiety in rat offspring exposed perinatally to low-dose bisphenol A. J Psychiatr Res. 2013 Oct;47(10): 1535-44. 
78 Walker DM, Goetz BM, Gore AC. Dynamic postnatal developmental and sex-specific neuroendocrine effects of prenatal polychlorinated biphenyls in rats. Mol Endocrinol. 2014 Jan;28(1):99-115.

79 Vazquez MJ, Toro CA, Castellano JM, RuizPino F, Roa J, Beiroa D, et al. SIRT1 mediates obesity- and nutrient-dependent perturbation of pubertal timing by epigenetically controlling Kiss1 expression. Nat Commun. 2018;9(1):4194.

80 Meister B. Control of food intake via leptin receptors in the hypothalamus. Vitam Horm. 2000;59:265-304. [Online]. Available from:

81 Farooqi IS. Leptin and the onset of puberty: insights from rodent and human genetics. Semin Reprod Med. 2002;20(2):139-44.

82 Halaas JL, Gajiwala KS, Maffei M, Cohen SL, Chait BT, Rabinowitz D, et al. Weight-reducing effects of the plasma protein encoded by the obese gene. Science. 1995;269(5223):5436.

83 Barash IA, Cheung CC, Weigle DS, Ren H, Kabigting EB, Kuijper JL, et al. Leptin is a metabolic signal to the reproductive system. Endocrinology. 1996;137(7):3144-7.

84 Chehab FF, Lim ME, Lu R. Correction of the sterility defect in homozygous obese female mice by treatment with the human recombinant leptin. Nat Genet. 1996 Mar;12(3):31820.

85 Lebrethon MC, Aganina A, Fournier M, Gérard A, Parent AS, Bourguignon JP. Effects of in vivo and in vitro administration of ghrelin, leptin and neuropeptide mediators on pulsatile gonadotrophin-releasing hormone secretion from male rat hypothalamus before and after puberty. J Neuroendocrinol. 2007 Mar; 19(3):181-8.

86 Quennell JH, Mulligan AC, Tups A, Liu X, Phipps SJ, Kemp CJ, et al. Leptin indirectly regulates gonadotropin-releasing hormone neuronal function. Endocrinology. 2009; 150(6):2805-12.

87 Manfredi-Lozano M, Roa J, Tena-Sempere M Connecting metabolism and gonadal function: novel central neuropeptide pathways involved in the metabolic control of puberty and fertility. Front Neuroendocrinol. 2018; 48:37-49.

88 Ross RA, Leon S, Madara JC, Schafer D, Fergani $\mathrm{C}$, Maguire CA, et al. PACAP neurons in the ventral premammillary nucleus regulate reproductive function in the female mouse. Elife. 2018;7:e35960.

89 Donato J, Cravo RM, Frazão R, Gautron L, Scott MM, Lachey J, et al. Leptin's effect on puberty in mice is relayed by the ventral premammillary nucleus and does not require signaling in Kiss1 neurons. J Clin Invest. 2011; 121(1):355-68

90 Martin C, Navarro VM, Simavli S, Vong L, Carroll RS, Lowell BB, et al. Leptin-responsive GABAergic neurons regulate fertility through pathways that result in reduced kisspeptinergic tone. J Neurosci. 2014;34(17):6047-56.
91 Bellefontaine N, Chachlaki K, Parkash J, Vanacker C, Colledge W, d'Anglemont de Tassigny $\mathrm{X}$, et al. Leptin-dependent neuronal NO signaling in the preoptic hypothalamus facilitates reproduction. J Clin Invest. 2014;124(6):2550-9.

92 Manfredi-Lozano M, Roa J, Ruiz-Pino F, Piet R, Garcia-Galiano D, Pineda R, et al. Defining a novel leptin-melanocortin-kisspeptin pathway involved in the metabolic control of puberty. Mol Metab. 2016 Oct; 5(10):844-57.

93 Bautista CJ, Boeck L, Larrea F, Nathanielsz PW, Zambrano E. Effects of a maternal low protein isocaloric diet on milk leptin and progeny serum leptin concentration and appetitive behavior in the first 21 days of neonatal life in the rat. Pediatr Res. 2008;63(4): 358-63.

94 Ramírez S, Claret M. Hypothalamic ER stress: a bridge between leptin resistance and obesity. FEBS Lett. 2015;589(14):1678-87.

95 Angle BM, Do RP, Ponzi D, Stahlhut RW, Drury BE, Nagel SC, et al. Metabolic disruption in male mice due to fetal exposure to low but not high doses of bisphenol A (BPA): evidence for effects on body weight, food intake, adipocytes, leptin, adiponectin, insulin and glucose regulation. Reprod Toxicol. 2013;42:256-68.

96 Newbold RR, Padilla-Banks E, Snyder RJ, Phillips TM, Jefferson WN. Developmental exposure to endocrine disruptors and the obesity epidemic. Reprod Toxicol. 2007 Apr; 23(3):290-6.

97 Ojeda S, Skinner M. Puberty in the rat. 3rd ed. San Diego: Academic Press/Elsevier; 2006. p. 2061-126.

98 Goroll D, Arias P, Wuttke W. Preoptic release of amino acid neurotransmitters evaluated in peripubertal and young adult female rats by push-pull perfusion. Neuroendocrinology. 1993;58(1):11-5.

99 Bourguignon J-P, Gerard A, Purnelle G, Czajkowski V, Yamanaka C, Lemaı M. Duality of glutamatergic and gabaergic control of pulsatile GnRH secretion by rat hypothalamic explants: II. Reduced NR2C- and GABA A-receptor-mediated inhibition at initiation of sexual maturation. J Neuroendocrinol. 1997;9:193-9.

100 Bourguignon J-P, Gérard A, Purnelle G, Czajkowski V, Yamanaka C, Lemaı M, et al. Duality of glutamatergic and gabaergic control of pulsatile $\mathrm{GnRH}$ secretion by rat hypothalamic explants: II. ReducedNR2C- and GABAA-receptor-mediated inhibition atinitiation of sexual maturation. J Neuroendocrinol. 1997;9(3):193-9.

101 Parent AS, Matagne V, Bourguignon JP. Control of puberty by excitatory amino acid neurotransmitters and its clinical implications. Endocrine. 2005;28(3):281-6.
102 Sullivan SD, Moenter SM. Gamma-aminobutyric acid neurons integrate and rapidly transmit permissive and inhibitory metabolic cues to gonadotropin-releasing hormone neurons. Endocrinology. 2004 Mar; 145(3): 1194-202.

103 Sullivan SD, DeFazio RA, Moenter SM. Metabolic regulation of fertility through presynaptic and postsynaptic signaling to gonadotropin-releasing hormone neurons. J Neurosci. 2003 Sep;23(24):8578-85.

104 Chu Z, Andrade J, Shupnik MA, Moenter SM. Differential regulation of gonadotropin-releasing hormone neuron activity and membrane properties by acutely applied estradiol: dependence on dose and estrogen receptor subtype. J Neurosci. 2009;29(17): 5616-27.

105 Kwakowsky A, Cheong RY, Herbison AE, Ábrahám IM. Non-classical effects of estradiol on cAMP responsive element binding protein phosphorylation in gonadotropinreleasing hormone neurons: mechanisms and role. Front Neuroendocrinol. 2014 Jan; 35(1):31-41.

106 Cabaton NJ, Canlet C, Wadia PR, TremblayFranco M, Gautier R, Molina J, et al. Effects of low doses of bisphenol A on the metabolome of perinatally exposed CD-1 mice. Environ Health Perspect. 2013;121(5):586-93.

107 Cardoso N, Pandolfi M, Lavalle J, Carbone S, Ponzo O, Scacchi P, et al. Probable gamma-aminobutyric acid involvement in bisphenol A effect at the hypothalamic level in adult male rats. J Physiol Biochem. 2011; 67(4):559-67.

108 Ogi H, Itoh K, Ikegaya H, Fushiki S. Alterations of neurotransmitter norepinephrine and gamma-aminobutyric acid correlate with murine behavioral perturbations related to bisphenol A exposure. Brain Dev. 2015 Sep;37(8):739-46.

109 Parent AS, Franssen D, Fudvoye J, Pinson A Bourguignon JP. Current changes in pubertal timing: revised vision in relation with environmental factors including endocrine disruptors. Endocr Dev. 2016;29:174-84.

110 Zhou R, Bai Y, Yang R, Zhu Y, Chi X, Li L, et al. Abnormal synaptic plasticity in basolateral amygdala may account for hyperactivity and attention-deficit in male rat exposed perinatally to low-dose bisphenol-A Neuropharmacology. 2011;60(5):789-98.

111 Franssen D, Gérard A, Hennuy B, Donneau AF, Bourguignon JP, Parent AS. Delayed neuroendocrine sexual maturation in female rats after a very low dose of bisphenol A through altered gabaergic neurotransmission and opposing effects of a high dose. Endocrinology. 2016;157(5):1740-50.

112 dos Santos NR, Rodrigues JLG, Bandeira MJ Anjos ALDS, Araújo CFS, Adan LFF, et al Manganese exposure and association with hormone imbalance in children living near a ferro-manganese alloy plant. Environ Res. 2019;172:166-74. 
113 Yang X, Tan J, Xu X, Yang H, Wu F, Xu B, et al. Prepubertal overexposure to manganese induce precocious puberty through GABAA receptor/nitric oxide pathway in immature female rats. Ecotoxicol Environ Saf. 2020 Jan;188:109898.

114 Gay VL, Plant TM. N-methyl-d, l-aspartate elicits hypothalamic gonadotropin-releasing hormone release in prepubertal male rhesus monkeys (macaca mulatto). Endocrinology. 1987;120(6):2289-96.

115 Smyth C, Wilkinson M. A critical period for glutamate receptor-mediated induction of precocious puberty in female rats. J Neuroendocrinol. 1994;6(3):275-84. [Online]. Available from:

116 Urbanski HF, Ojeda SR. Activation of luteinizing hormone-releasing hormone release advances the onset of female puberty. Neuroendocrinology. 1987;46(3):273-6.

117 Meijs-Roelofs HM, Kramer P, van Leeuwen EC. The N-methyl-d-aspartate receptor antagonist MK-801 delays the onset of puberty and may acutely block the first spontaneous LH surge and ovulation in the rat. J Endocrinol. 1991;131(3):435-41.

118 Urbanski HF, Ojeda SR. A role for n-methyl$\mathrm{d}$-aspartate (NMDA) receptors in the control of lh secretion and initiation of female puberty. Endocrinology. 1990;126(3):17746.

119 Urbanski HF, Ojeda SR. A role for N-methyl-D-aspartate (NMDA) receptors in the control of LH secretion and initiation of female puberty. Endocrinology. 1990 Mar; 126(3):1774-6.

120 Bourguignon JP, Gérard A, Franchimont P. Direct activation of gonadotropin-releasing hormone secretion through different receptors to neuroexcitatory amino acids. Neuroendocrinology. 1989;49(4):402-8.

121 Bourguignon JP, Gerard A, Mathieu J, Mathieu A, Franchimont P. Maturation of the hypothalamic control of pulsatile gonadotropin-releasing hormone secretion at onset of puberty. I. Increased activation of $\mathrm{N}$ methyl-D-aspartate receptors. Endocrinology. 1990;127(2):873-81.

122 Zhang H, Kuang H, Luo Y, Liu S, Meng L, Pang Q, et al. Low-dose bisphenol A exposure impairs learning and memory ability with alterations of neuromorphology and neurotransmitters in rats. Sci Total Environ. 2019;697:134036.

123 Chen Z, Li T, Zhang L, Wang H, Hu F. Bisphenol A exposure remodels cognition of male rats attributable to excitatory alterations in the hippocampus and visual cortex. Toxicology. 2018;410:132-41.

124 Alavian-Ghavanini A, Lin PI, Lind PM, Risén Rimfors S, Halin Lejonklou M, Dunder $\mathrm{L}$, et al. Prenatal bisphenol A exposure is linked to epigenetic changes in glutamate receptor subunit gene grin $2 b$ in female rats and humans. Sci Rep. 2018;8(1):11315.
125 Dickerson SM, Cunningham SL, Gore AC. Prenatal PCBs disrupt early neuroendocrine development of the rat hypothalamus. Toxicol Appl Pharmacol. 2011;252(1):36-46.

126 Rasier G, Parent AS, Gérard A, Lebrethon MC, Bourguignon JP. Early maturation of gonadotropin-releasing hormone secretion and sexual precocity after exposure of infant female rats to estradiol or dichlorodiphenyltrichloroethane. Biol Reprod. 2007 Oct; 77(4):734-42.

127 Rasier G, Parent A-S, Gérard A, Denooz R, Lebrethon M-C, Charlier C, et al. Mechanisms of interaction of endocrine-disrupting chemicals with glutamate-evoked secretion of gonadotropin-releasing hormone. Toxicol Sci. 2008 Mar;102(1):33-41.

128 Cardoso N, Pandolfi M, Ponzo O, Carbone S, Szwarcfarb B, Scacchi P, et al. Evidence to suggest glutamic acid involvement in Bisphenol A effect at the hypothalamic level in prepubertal male rats. Neuro Endocrinol Lett. 2010;31(4):512-6.

129 Lopez-Rodriguez D, Franssen D, Sevrin E, Gérard A, Balsat C, Blacher S, et al. Persistent vs transient alteration of folliculogenesis and estrous cycle after neonatal vs adult exposure to bisphenol A. Endocrinology. 2019 Nov;160(11):2558-72.

130 Lund C, Yellapragada V, Vuoristo S, Balboa D, Trova S, Allet C, et al. Characterization of the human GnRH neuron developmental transcriptome using a GNRH1-TdTomato reporter line in human pluripotent stem cells. Dis Model Mech. 2020;13(3): dmm040105.

131 Lund C, Pulli K, Yellapragada V, Giacobini P, Lundin K, Vuoristo S, et al. Development of gonadotropin-releasing hormone-secreting neurons from human pluripotent stem cells. Stem Cell Rep. 2016;7(2):149-57.

132 Mueller JK, Heger S. Endocrine disrupting chemicals affect the gonadotropin releasing hormone neuronal network. Reprod Toxicol. 2014;44:73-84.

133 Mcllwraith EK, Loganathan N, Belsham DD. Phoenixin expression is regulated by the fatty acids palmitate, docosahexaenoic acid and oleate, and the endocrine disrupting chemical bisphenol a in immortalized hypothalamic neurons. Front Neurosci. 2018 Nov; $12: 838$.

134 Merkle FT, Maroof A, Wataya T, Sasai Y, Studer L, Eggan K, et al. Generation of neuropeptidergic hypothalamic neurons from human pluripotent stem cells. Development. 2015;142(4):633-43.

135 Enright HA, Lam D, Sebastian A, Sales AP, Cadena J, Hum NR, et al. Functional and transcriptional characterization of complex neuronal co-cultures. Sci Rep. 2020 Dec; 10(1):11007.

136 Ibáñez L, Díaz R, López-Bermejo A, Marcos MV. Clinical spectrum of premature pubarche: links to metabolic syndrome and ovarian hyperandrogenism. Rev Endocr Metab Disord. 2009 Mar;10(1):63-76.
137 Carter R, Jaccard J, Silverman WK, Pina AA Pubertal timing and its link to behavioral and emotional problems among 'at-risk' African American adolescent girls. J Adolesc. 2009;32(3):467-81.

138 Lakshman R, Forouhi NG, Sharp SJ, Luben R, Bingham SA, Khaw KT, et al. Early age at menarche associated with cardiovascular disease and mortality. J Clin Endocrinol Metab. 2009;94(12):4953-60.

139 Lakshman R, Forouhi N, Luben R, Bingham S, Khaw K, Wareham N, et al. Association between age at menarche and risk of diabetes in adults: results from the EPIC-Norfolk cohort study. Diabetologia. 2008;51(5):781-6.

140 Vazquez MJ, Velasco I, Tena-Sempere M. Novel mechanisms for the metabolic control of puberty: implications for pubertal alterations in early-onset obesity and malnutrition. J Endocrinol. 2019 Aug;242(2):R5165.

141 Abreu AP, Toro CA, Song YB, Navarro VM Bosch MA, Eren A, et al. MKRN3 inhibits the reproductive axis through actions in kisspeptin-expressing neurons. J Clin Invest. 2020 Aug;140(8):4486-500.

142 Heras V, Sangiao-Alvarellos S, ManfrediLozano M, Sanchez-Tapia MJ, Ruiz-Pino F, Roa J, et al. Hypothalamic miR-30 regulates puberty onset via repression of the pubertysuppressing factor, Mkrn3. PLoS Biol. 2019 Nov;17(11):e3000532.

143 Lomniczi A, Aylwin C, Vigh-Conrad K. The emerging role of chromatin remodeling factors in female pubertal development. Neuroendocrinology. 2019;109(3):208-17.

144 Sangiao-Alvarellos S, Manfredi-Lozano M, Ruiz-Pino F, Navarro VM, Sánchez-Garrido MA, Leon S, et al. Changes in hypothalamic expression of the Lin28/let-7 system and related microRNAs during postnatal maturation and after experimental manipulations of puberty. Endocrinology. 2013;154(2): 942-55.

145 Pillon D, Cadiou V, Angulo L, Duittoz AH Maternal exposure to 17-alpha-ethinylestradiol alters embryonic development of GnRH-1 neurons in mouse. Brain Res. 2012 Jan; 1433:29-37.

146 Vosges M, Le Page Y, Chung BC, Combarnous Y, Porcher JM, Kah O, et al. 17alphaethinylestradiol disrupts the ontogeny of the forebrain GnRH system and the expression of brain aromatase during early development of zebrafish. Aquat Toxicol. 2010 Sep; 99(4):479-91.

147 Johansson HKL, Damdimopoulou P, van Duursen MBM, Boberg J, Franssen D, de Cock $\mathrm{M}$, et al. Putative adverse outcome pathways for female reproductive disorders to improve testing and regulation of chemicals. Arch Toxicol. 2020 Oct 1;94(10):335979 .

Franssen/Svingen/Lopez Rodriguez/

Van Duursen/Boberg/Parent 